\title{
Malignant melanoma in the Czech Republic: Incidence and mortality according to sex, age and disease stage
}

\author{
Jana Vranova ${ }^{a}$, Monika Arenbergerovab ${ }^{b}$, Petr Arenberger ${ }^{b}$, Antonin Vranac, Jozef Zivcak ${ }^{d}$, Hana Kolarova ${ }^{e}$, Jozef Rosina ${ }^{\text {fa }}$
}

Background. The Czech Republic has reported one of the highest incidence rates of cutaneous melanoma (CM) in Europe and the rate continues to rise. Our study undertook a detailed investigation of the incidence and mortality of melanoma relative to sex, age and disease stage. The main goals were to elucidate the causes of the rising trends and explain the differences in development relative to sex, age and disease stage.

Methods and Results. The estimated annual percentage change (EAPC) using the Joinpoint Regression Model was calculated separately for men and women for all age categories and for all T stages of TNM classification. The EAPC for women was slightly higher than for men. This was only found in melanomas thinner than $1 \mathrm{~mm}$ (T1). For all other stages (T2, T3 and T4) the situation was worse in men. A higher incidence rate of CM and the higher value of EAPC were found for women in younger age categories (up to 49 years). In the next age category, from 50 to 59 years, the incidence of CM was comparable in both sexes as well as the EAPC. In the older age categories, i.e. 60 years and older, a significant increase was found predominantly in men. The mortality rates were only comparable between men and women in the 20 to 29 year age group. In all other categories there was a higher mortality for men.

Conclusions. The number of melanoma cases in the Czech Republic is increasing faster than any other cancer. Despite improved survival rates, the death rate from $\mathrm{CM}$ continues to climb as a result of exponential increases in incidence. Thus primary and secondary prevention campaigns are essential for future reductions in CM incidence and mortality in the Czech Republic.

Key words: incidence, mortality, cutaneous melanoma, prevention campaign, risk factors, estimated annual percentage change, biomedical engineering

Received: February 24, 2012; Accepted with revision: July 24, 2012; Available online: November 2, 2012 http://dx.doi.org/10.5507/bp.2012.081

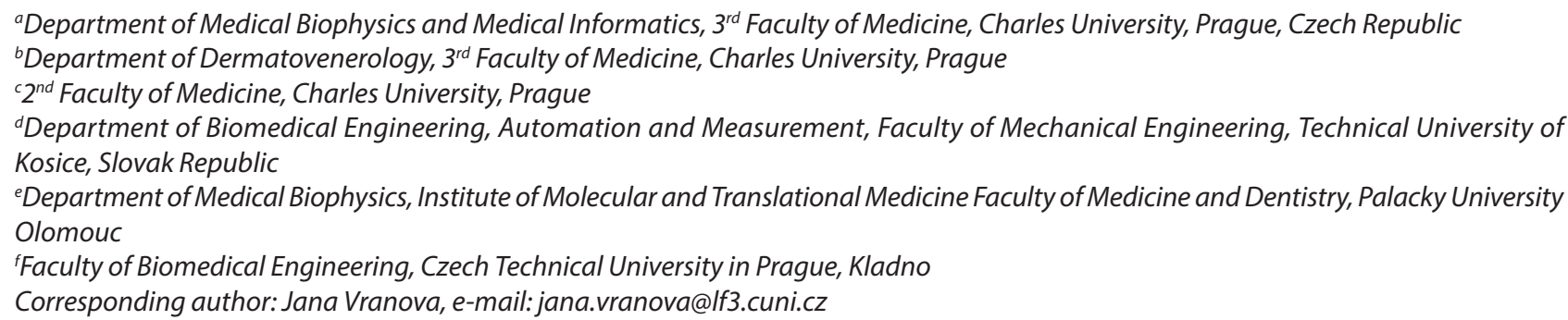

\section{INTRODUCTION}

Skin cancers are the most common human cancer in the Caucasian population and the incidence during the past decades has increased rapidly in many countries ${ }^{1-3}$, including the Czech Republic. Although cutaneous melanoma (CM) is only $10 \%$ of all skin cancer cases, it is considerably more dangerous and in many diagnosed cases leads to death ${ }^{4}$.

Melanoma incidence rates normally increase with proximity to the Equator ${ }^{5}$ but in Europe, an inverse pattern is found, with the highest incidence rates in Iceland, Scandinavia, United Kingdom, Germany and Denmark ${ }^{6}$. Exceptions are the Central European mountainous countries of Switzerland and Austria with high altitudes ${ }^{1,7,8}$ and surprisingly the Czech Republic with higher incidence of melanoma than surrounding countries (Fig. 1) (ref. ${ }^{9}$ ).

Among men, the Czech Republic was found to have the fifth highest documented incidence rate of skin cancer in Europe in 2008 (ref. ${ }^{9}$ ); among women the situation was slightly better. Cutaneous melanoma is the sixth most common malignancy in men and fifth in women. In 2008 $\mathrm{CM}$ was identified in 8,420 men and in 10,726 women. For men the only cancers more common than $\mathrm{CM}$ were (rank highest to lowest) prostate cancer (number of surviving and diseased persons $n=28,422$ ), colon neoplasm $(n=14,281)$, cancer of the kidney, cancer of the rectum, and cancer of the anus and anal canal. For women, the only cancers more common than $\mathrm{CM}$ were breast cancer $(n=60,764)$, cancer of the uterus $(n=22,640)$, cervical cancer and colorectal carcinoma. The prevalence, including the number of surviving and diseased persons was taken from the National Cancer Registry (NCR) for 1976-2008.

The dramatic change in crude incidence and crude mortality in the Czech Republic is illustrated by the following data ${ }^{10}$ : while in 1970 the crude incidence of CM was 3.1 in men and 3.2 per 100,000 inhabitants in women, the data from 2008 showed the incidence to be 


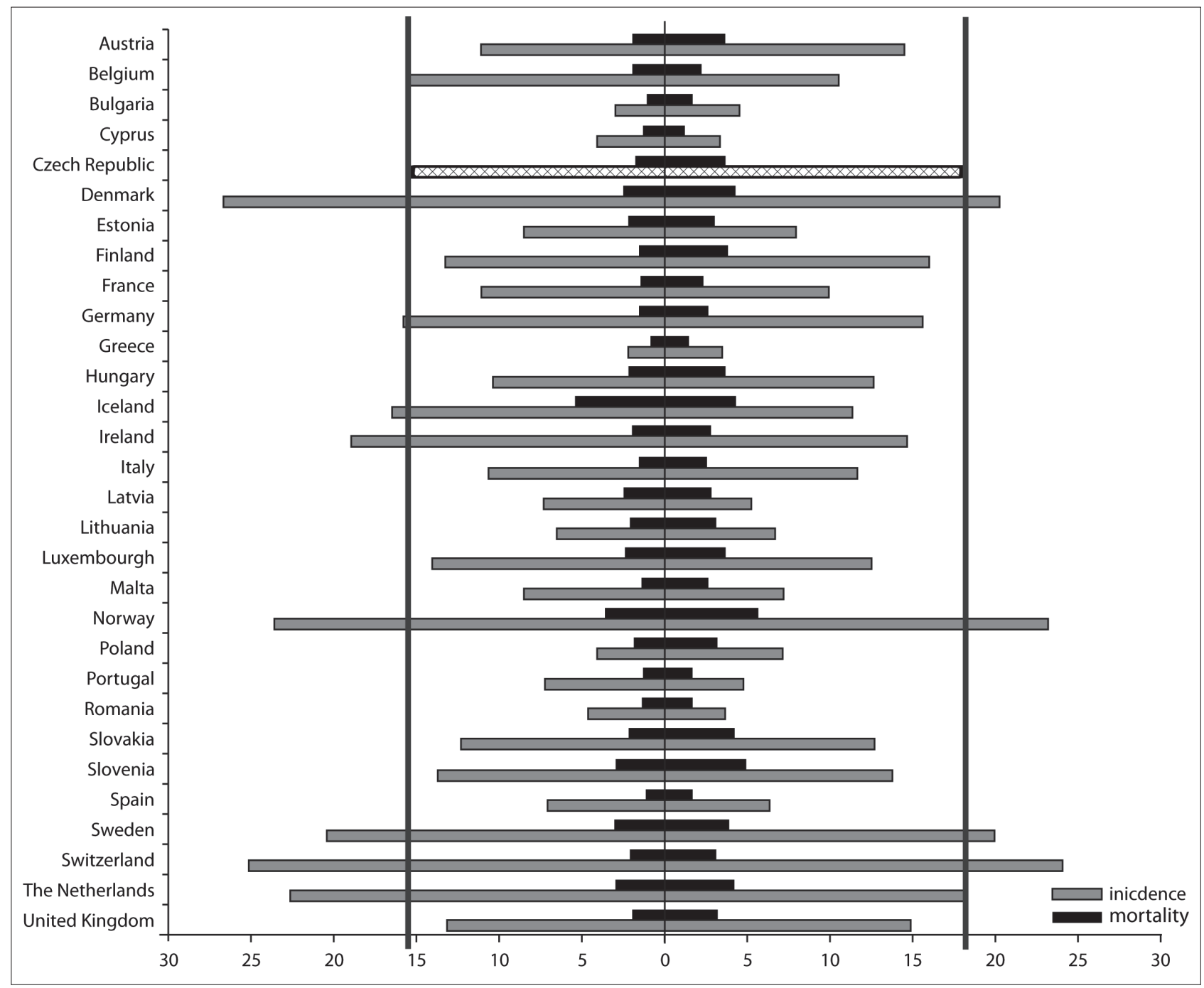

Fig. 1. Incidence and mortality in Europe, year 2008 estimates, by country (age-adjusted rate/100,000). Source: European Cancer Observatory ${ }^{9}$

19.6 in men and 16.0 per 100,000 inhabitants in women. Mortality in 1970 in men and women was 1.8 and 1.6 per 100000 inhabitants, respectively. However, by 2008 it had risen to 3.7 per 100,000 inhabitants in men and 3.0 per 100,000 inhabitants in women. It can be seen that over the past 40 years, the incidence of CM in the Czech Republic has risen by more than $600 \%$. The exponential growth of incidence of cutaneous melanoma in both men and women is shown in Fig. 2.

The alarming increase in melanoma in the Czech Republic motivated our detailed investigation of the incidence and mortality according to sex, age and stage of disease. The goals were to determine possible causes of the dramatic increase and explain the trends and differences in trends relative to incidence and mortality rates from the point of view mentioned above.

\section{MATERIALS AND METHODS}

Data from the National Cancer Registry of the Czech Republic were used in this study ${ }^{10}$. The NCR was established in 1976. It is part of the Institute of Health
Information and Statistics for the Czech Republic which is a government organization founded by the Ministry of Health. The purpose of the NCR is the registration of malignant neoplasms and periodic monitoring of their further development. The NCR provides summary data for statistical reporting at national and international levels, as well as for epidemiological studies and medical research. In 2006 a significant change in the methodology of data collection occurred. The data structure, including the basis of collection and acquisition were reassessed. The NCR is a member of The International Association of Cancer Registries in Lyon, and cooperates with the European Network of Cancer Registries and maintains contact with foreign registries. Data on malignant neoplasms in the Czech Republic were published in Volumes VI-IX of Cancer Incidence in Five Continents and have been used in many international projects and studies.

The data from the NCR also provides information regarding disease stage and histology, as well as information regarding the spread of $\mathrm{CM}$ in different age categories.

One of the objectives of our study was its use in comparisons of occurrence of different stages of CM in populations in different countries. International comparisons 


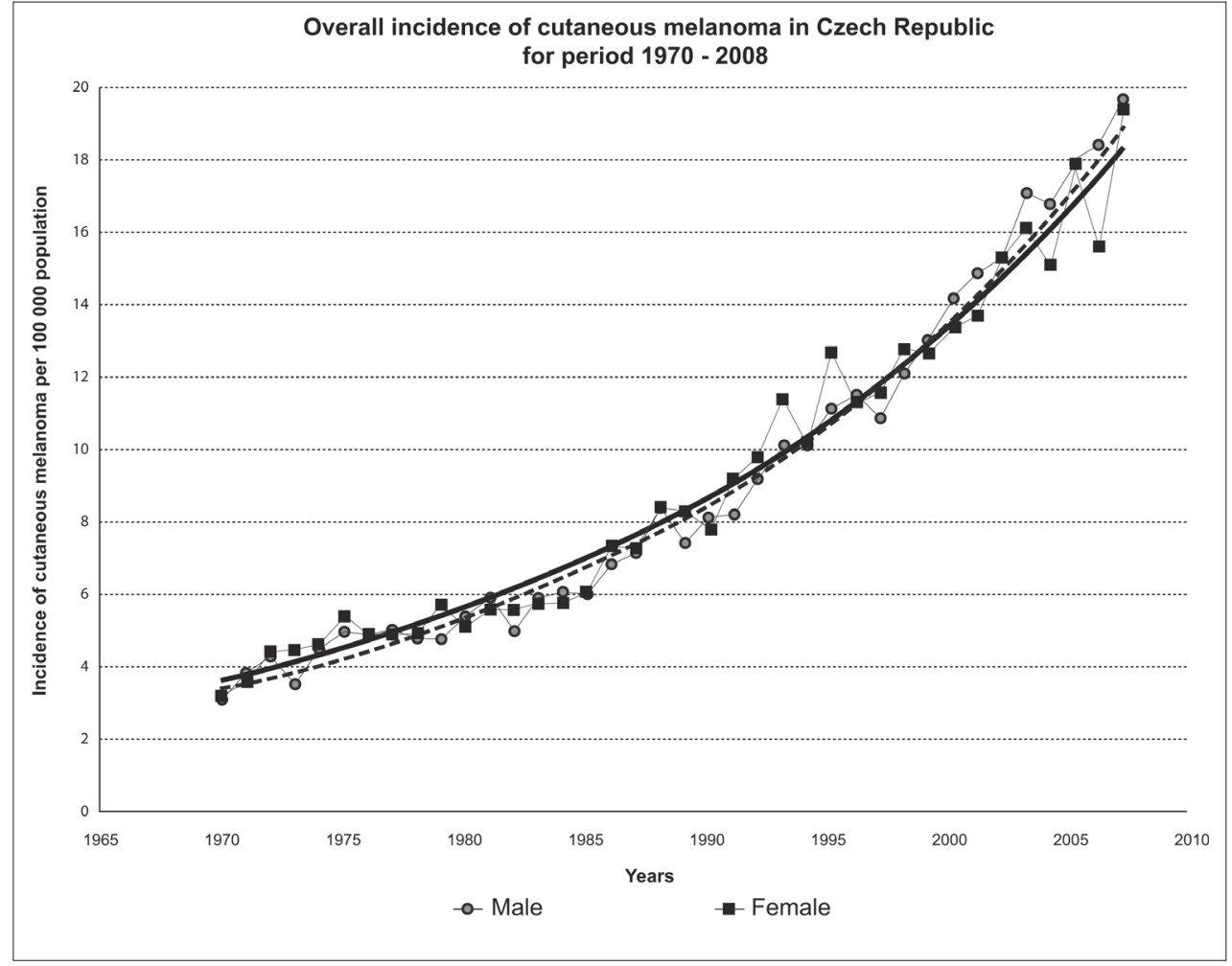

Fig. 2. Raw incidence per 100,000 inhabitants of cutaneous melanoma in the Czech Republic in men and women (1970-2008).

Table 1. Estimated Annual Percent Change for incidence and mortality rate of cutaneous melanoma according to T stage of TNM classification for men and women.

\begin{tabular}{ccccc}
\hline \multirow{2}{*}{$\begin{array}{c}\text { TNM } \\
\text { classification }\end{array}$} & \multicolumn{2}{c}{ EAPC of Incidence } & \multicolumn{2}{c}{ EAPC of Mortality } \\
\cline { 2 - 5 } & Male & Female & Male & Female \\
\hline T1 & $37.22 \%$ & $38.65 \%$ & $3.67 \%$ & $2.56 \%$ \\
T2 & $11.78 \%$ & $10.90 \%$ & $4.92 \%$ & $2.14 \%$ \\
T3 & $11.05 \%$ & $8.19 \%$ & $4.16 \%$ & $3.84 \%$ \\
T4 & $5.66 \%$ & $4.15 \%$ & & $2.33 \%$ \\
\hline
\end{tabular}

are complicated due to inconsistent methodology used in monitoring the stages of malignant melanoma. Various national registries used different classification systems, such as the TNM classification, Breslow thickness or Clark level. In recent years a new classification system for prediction of overall survival and recurrence-free survival, based on findings in the sentinel lymph node (SLN), has been used. Sentinel node biopsy is not suitable for all situations and it is important that the surgeon has been trained in this procedure and has validated his/her results with the technique. The SLN classification was not used in this study since it can only be used on tumors with specific characteristics and because it is not included in the national registry (NCR).

In a comparative study ${ }^{1}$ the authors unified classification schemes using T1 - T4. Therefore our study of the incidence and the mortality was also evaluated according to TNM classification. In situ melanomas were not included in our estimations. TNM classification of malignant neoplasms, $6^{\text {th }}$ edition, Czech version 2004, IHIS CR was used.
To compare trends in the evolution of the incidence of CM, according to TNM classification and according to age categories, between men and women in the Czech Republic for the period 1977-2008 (ref. ${ }^{11}$ ) the estimated annual percentage change (EAPC) was calculated using the Joinpoint Regression Model ${ }^{12}$.

\section{RESULTS}

\section{TNM classification}

The development of incidence and mortality of CM according to the TNM classification and its comparison between men and women are shown in detail in Figs. 3a - 3h. The computed estimated annual percentage changes for T stages of the TNM classification are summarized in Table 1.

The increase in incidence of CM was essentially due to a rapid continuous increase in melanomas thinner than $1 \mathrm{~mm}$ in both sexes with an EAPC of $37.22 \%$ for men and a slightly higher EAPC of $38.65 \%$ for women, over 


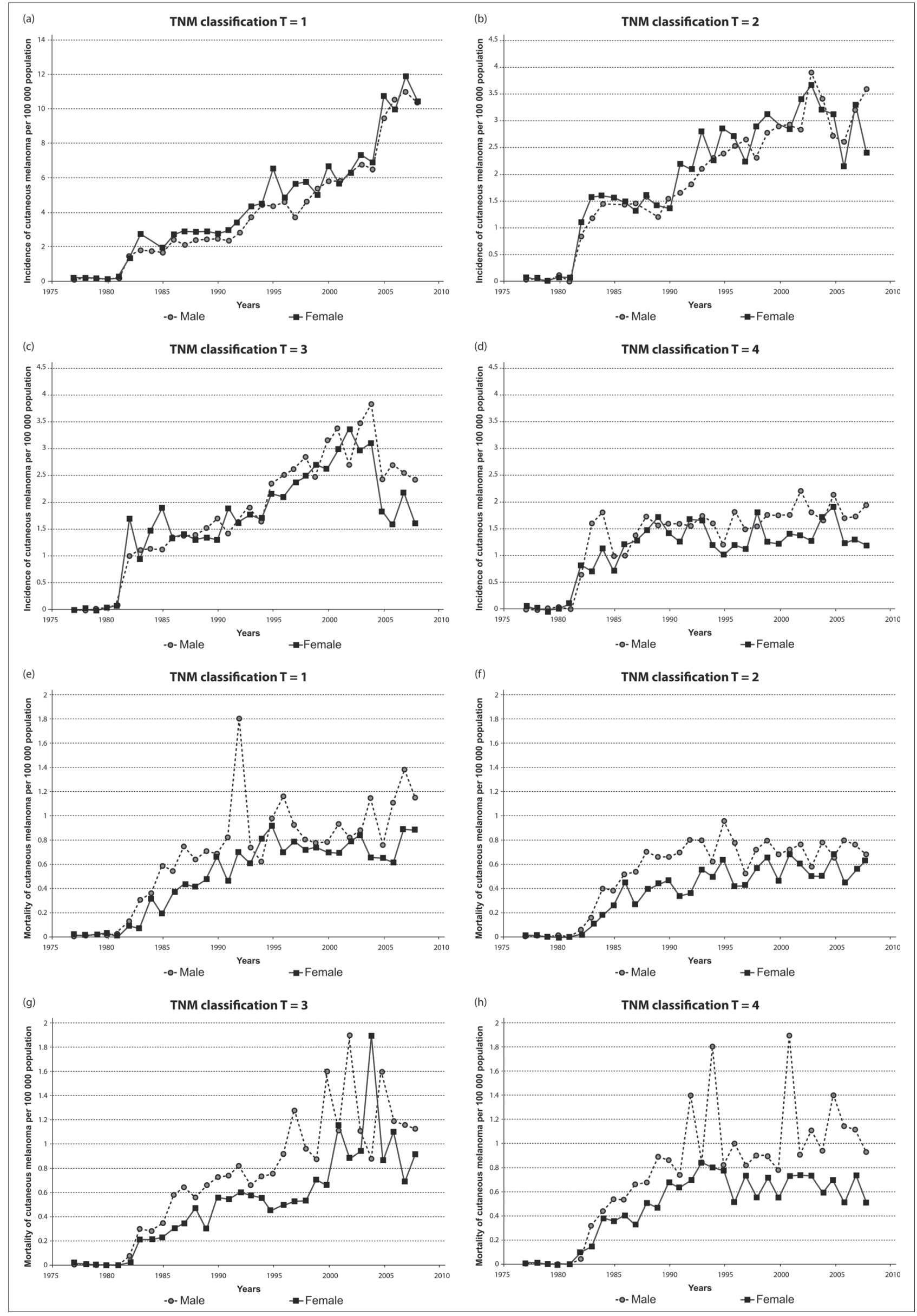

Fig. 3. Incidence and mortality according to TNM classification (1977-2008). Comparison between men and women. 


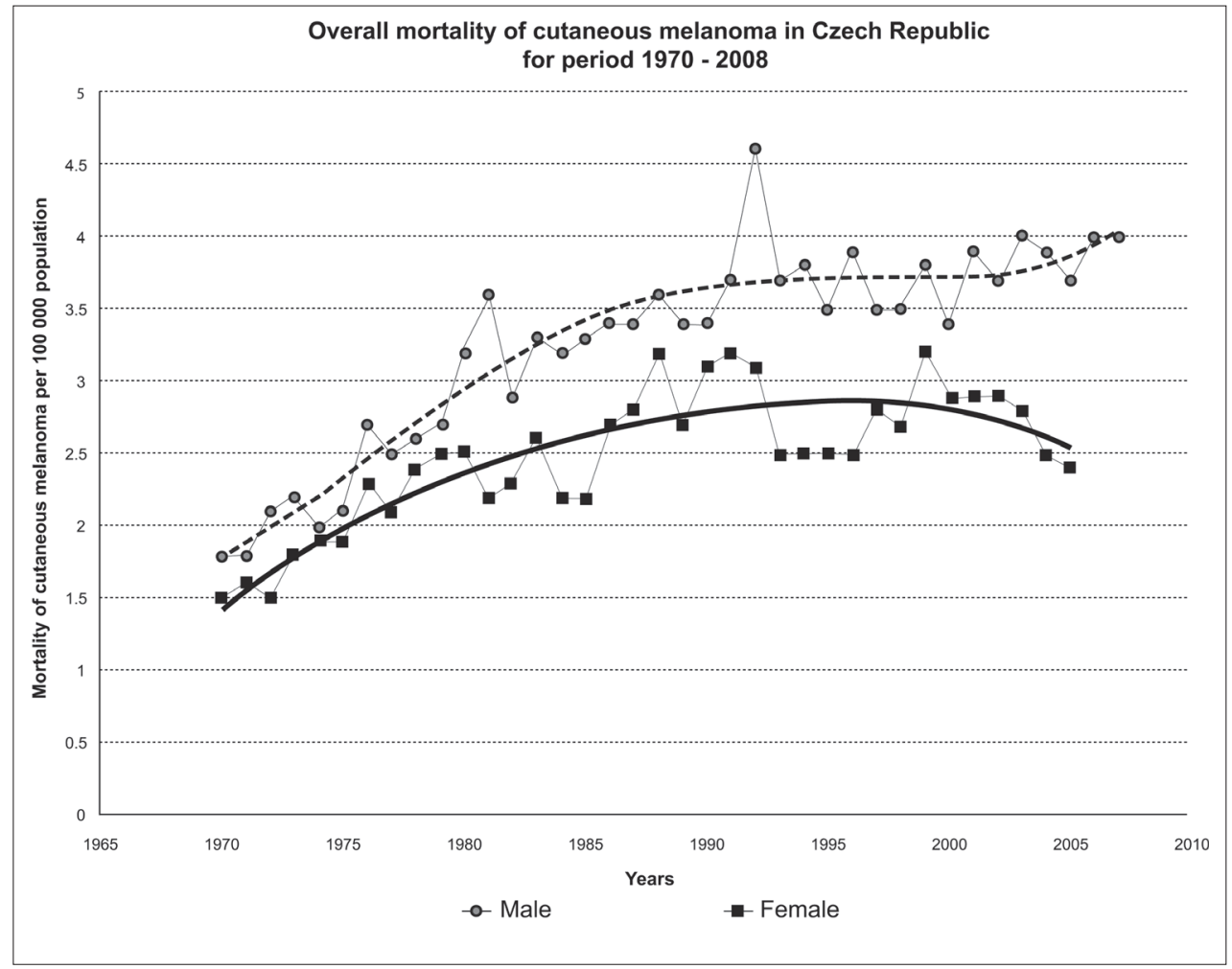

Fig. 4. Raw mortality per 100,000 inhabitants of cutaneous melanoma in the Czech Republic in men and women (1970-2008).

Table 2. Estimated Annual Percent Change for incidence and mortality rate of cutaneous melanoma according to age category for men and women.

\begin{tabular}{crrrr}
\hline \multirow{2}{*}{$\begin{array}{c}\text { TNM } \\
\text { classification }\end{array}$} & \multicolumn{2}{c}{ EAPC of Incidence } & \multicolumn{2}{c}{ EAPC of Mortality } \\
\cline { 2 - 5 } & \multicolumn{1}{c}{ Male } & Female & Male & Female \\
\hline $20-29$ & $4.53 \%$ & $12.16 \%$ & $-0.75 \%$ & $-0.75 \%$ \\
$30-39$ & $13.24 \%$ & $22.29 \%$ & $-2.62 \%$ & $-1.31 \%$ \\
$40-49$ & $29.30 \%$ & $50.61 \%$ & $-0.88 \%$ & $2.10 \%$ \\
$50-59$ & $72.67 \%$ & $78.51 \%$ & $2.46 \%$ & $6.85 \%$ \\
$60-69$ & $262.81 \%$ & $125.44 \%$ & $26.09 \%$ & $11.57 \%$ \\
$70-79$ & $1058.83 \%$ & $205.08 \%$ & $95.64 \%$ & $35.97 \%$ \\
$80+$ & $1824.21 \%$ & $250.89 \%$ & $303.66 \%$ & $77.94 \%$ \\
\hline
\end{tabular}

the whole period. For all other melanomas classifications with thickness greater than $1 \mathrm{~mm}$ the situation for women was better than for men: for melanomas with thickness between $1 \mathrm{~mm}$ and $2 \mathrm{~mm}$, a continued increase was observed in men with an EAPC of $11.78 \%$, while in women a smaller increase was noted, with an EAPC of $10.90 \%$. For melanomas with a thickness between $2 \mathrm{~mm}$ and $4 \mathrm{~mm}$, the EAPC for women was only $8.19 \%$, while in men the EAPC was $11.05 \%$. For melanomas greater than $4 \mathrm{~mm}$, the EAPC for women was $4.15 \%$, and for men the EAPC was $5.66 \%$.

The situation regarding the incidence of $\mathrm{CM}$ relative to the stage of the disease is consistent with the estimated annual percentage changes of mortality rate for $\mathrm{T}$ stages and explains the discrepancy between overall mortality trends for men and women. Women have thinner tumors overall because they tend to have a more timely response to health advice and have potential lesions evaluated earlier than men who present with a greater proportion of thicker tumors and nodular lesions. In addition, there is debate of over a possible protective role of estrogen in melanoma development ${ }^{13}$. These facts appear to explain the leveling-off or even a decline in mortality in women since 1993. In contrast, the steady increase of CM mortality in men is still evident. The evolution in raw mortality for both men and women for the period 1970 - 2008 are shown in Fig. 4.

\section{Age categories}

The development of CM incidence according to age categories and the comparison between men and women is presented in Figs. 5a-5n. The computed estimated annual percentage changes of both, incidence and mortality, for age categories are summarized in Table 2.

The higher incidence rate of CM and higher EAPC values were found in the younger age categories (up to 49 years) in women. For ages 50 to 59 years the incidence of CM was comparable in both sexes as are EAPC values. 


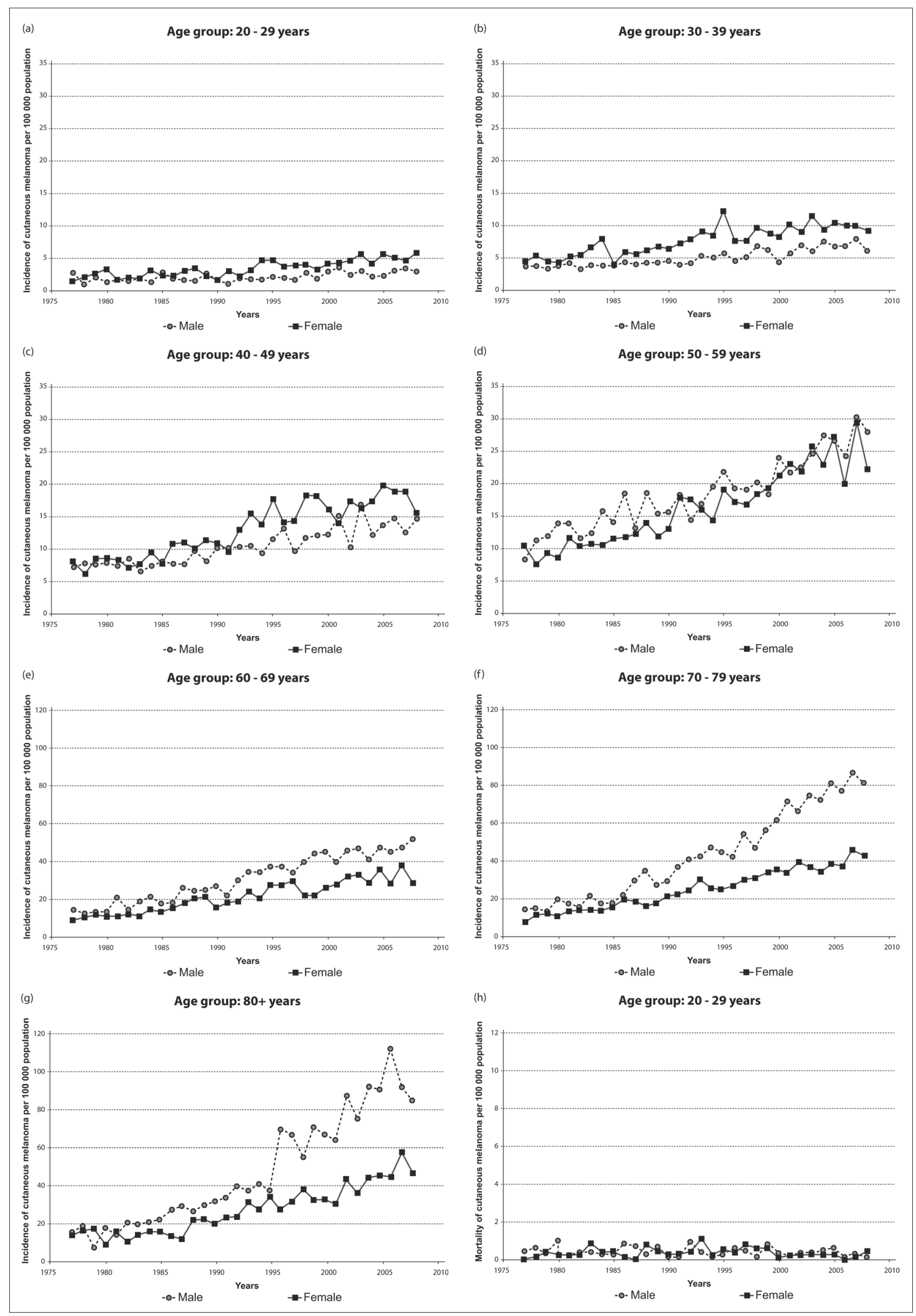

Fig. 5. Incidence and mortality according to the age categories (1977-2008). Comparison between men and women. 

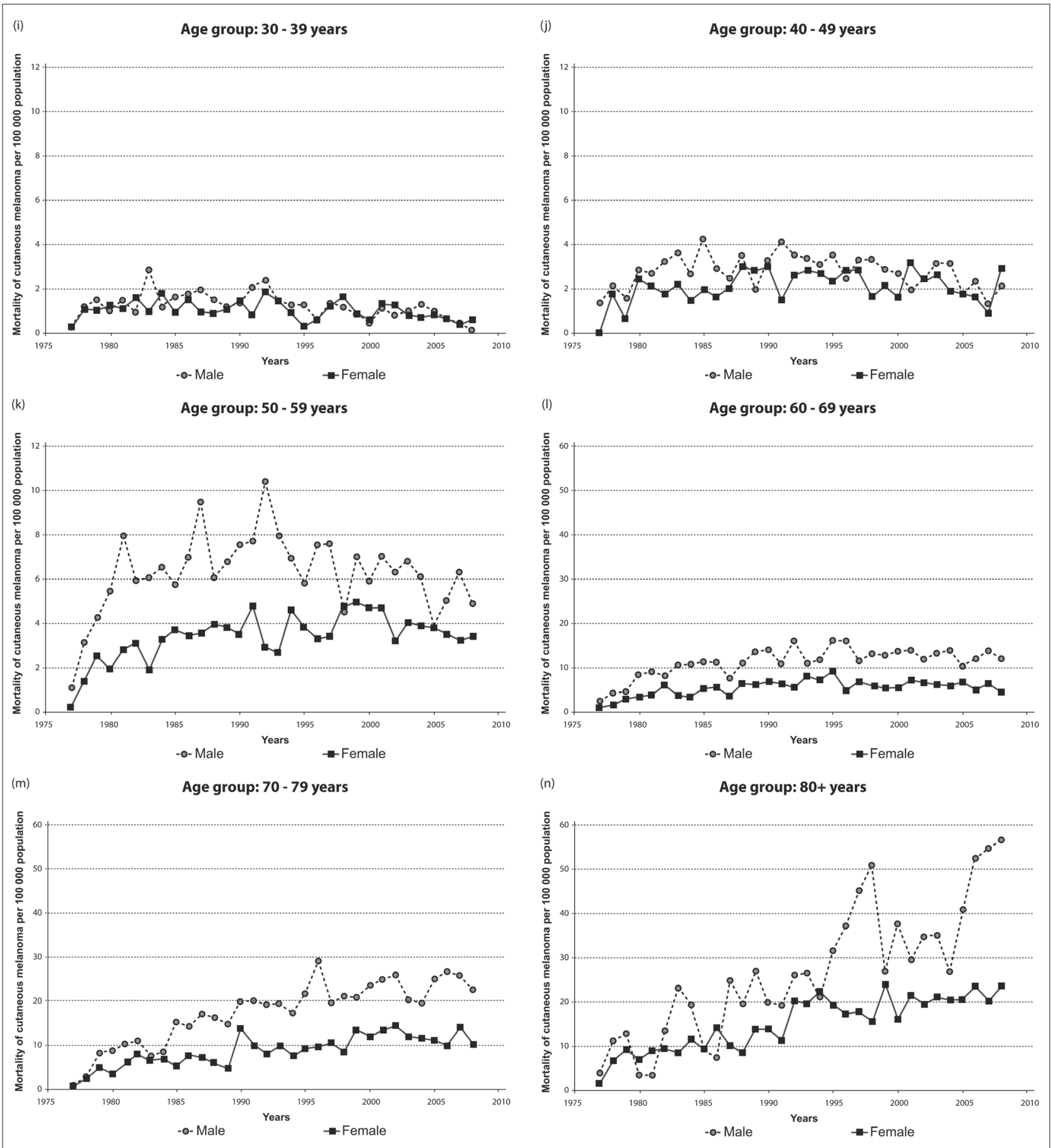

Fig. 5. Continued.

In the older age categories ( $\geq 60$ years) the situation was reversed - a dramatic increase was found predominantly in men; the increase in the incidence of cutaneous melanoma was somewhat less dramatic in women, but still alarming.

The only mortality rates in men and women that were comparable were in the 20 to 29 years age group. In all other categories men had higher mortality rates. In the age categories from $30-39,40-49$ and $50-59$ years a greater decrease or at least a more moderate increase of raw mortality in men was observed compared to women. This trend should be a wake-up-call for Czech women, particularly in the 40-49 and 50-59 years age groups, where a relatively high increase was found. In the older age categories ( $\geq 60$ years) a substantial increase in EAPC was seen in both sexes. The increase, as before, was much higher in men than in women. 


\section{DISCUSSION}

Epidemiological studies have shown considerable variation in the incidence rates of $\mathrm{CM}$ worldwide. Data suggest more favorable incidence trends in some countries while in others the incidence of CM is still rising ${ }^{14-19}$. Recent evidence suggests that the current rising trend in incidence of CM is due to improved surveillance techniques and early diagnosis, together with changes in lifestyle in terms of excessive recreational exposure to sunlight. The overall increases in CM incidence have begun to slow in recent years in Western Europe and North America. One explanation for the slowing in $\mathrm{CM}$ incidence rates in these countries is decreased sun exposure of the type likely to cause CM (improved sun exposure behavior), particularly in areas of the body normally covered by clothes. With effective skin cancer prevention campaigns and public education, further declines in incidence can be expected over the coming years ${ }^{20,21}$.

This general rule was partly confirmed in our study. The higher incidence rate of CM and the higher values of EAPC were observed in women in younger age categories, i.e. up to 49 years. The explanation may be connected with the misuse of sun tanning devices by those 20 to 29 (or younger) in the early nineties as well as increased travel to areas with high sun risks after the borders were opened. From the end of 1989 to 1991, 6000 new travel agencies were founded in the Czech Republic (WTO 2011). This increase incidence may be attributable to expanded use of indoor tanning - solaria visits ${ }^{22-24}$ predominantly by young women. There is no epidemiology data in this area accessible in the Czech Republic. In the age category from 50 to 59 years, the incidence of CM is comparable in both sexes as well as the EAPC, which may be also connected with exposure behavior in families spending holidays at lakes, at the seaside or in the mountains ${ }^{25}$. In the older age categories, i.e. 60 years and older, the situation is reversed - a substantial increase was found predominantly in men, which could be explained by leisure (skiing or mountaineering) or lifelong skin exposure to an ozone depleted environment.

Mortality data shows that the greatest similarity between men and women was in the age group from 20 to 29 years, where both sexes underestimate the risk of visible signs of skin disease. In all other categories men had higher mortality; it appears that in men underestimation of visible signs of skin disease continues throughout life. The influence of public campaigns concerning CM would probably benefit males in age categories 30 - 59 years where a slight decrease or at least a more moderate increase in raw mortality in men has been recently observed. This means that in Czech women, particularly in ages 40-59 years, quite a high increase has been observed. This rising trend is related to inappropriate sun exposure behavior when they were younger, particularly when they were adolescent girls, when a sun-tanned, slim body was still the symbol of health, happiness and prosperity. In a study by Lupton and Gaffney ${ }^{26,27}$, adolescent girls deliberately used sunscreen with a low protection factor (SPF) and also delayed sunscreen application in order to get a tan, despite being well educated regarding the potential danger and harm of sun overexposure.

Our EAPC evaluation is bringing a new view to Czech CM statistics showing almost parallel increases in both sexes particularly in elderly persons, but with much higher values in men than in women. Epidemiology studies have shown clearly that there is both a constitutional and an environmental contribution to melanoma risk, with sunlight being the major risk factor in the environment ${ }^{28,29}$. The data also clearly show that the thickness of a melanoma at the time it is removed is one of the major determinants of metastasis and, as such, long-term prognosis. Primary prevention programs in the Czech Republic have been aimed at reducing the desire for a tan and the related overexposure to sunlight ${ }^{30,31}$. Secondary prevention, which means education regarding early detection, has encouraged Czechs to seek early attention if they notice a new or changing pigmented lesion. Although we have shown that the age-adjusted incidence and mortality rates for the Czech Republic continue to rise, cohort analysis of both incidence and mortality rates reveals that the overall rise is not reflected in all age groups. In environmentally trained Czechs, i.e. those that have been influenced by our public health campaigns in recent decades, both incidence and mortality rates are dropping.

We may conclude that the number of melanoma cases is increasing faster than any other cancer in the Czech Republic. Incidence trends showed that most of the increased incidence can be ascribed to increased numbers of thinner, less aggressive superficially spreading melanomas. Despite improved survival rates, the death rate from $\mathrm{CM}$ continues to climb as a result of exponential increases in incidence, making it a major public health problem for the foreseeable future. The epidemiological data has confirmed that the major environmental risk factor for $\mathrm{CM}$ is intermittent intensive sunlight exposure. Primary and secondary prevention campaigns are essential for further reduction of the incidence and mortality from $\mathrm{CM}$ in the future ${ }^{32,33}$.

\section{ACKNOWLEDGEMENTS}

This work was supported by the grant project CZ.1.05/2.1.00/01.0030.

Authorship contributions: AV, JZ: literature search; JV, MA, PA: manuscript writing; JV, PA, JR: study design; HK: data collection; JV, PA: data analysis; JV, MA, PA, HK: data interpretation; JV, AV, JZ: statistical analysis and figures; JV, PA, JR: final approval.

Conflict of interest statement: None declared.

\section{REFERENCES}

1. De Vries E, Coebergh JW. Cutaneous Melanoma in Europe. European Journal of Cancer 2004;40:2355-66.

2. Parkin DM, Whelan SL, Ferlay J, Storm H. Cancer incidence in five continents I. - VIII. IARC Cancer Base No 7. Lyon;2007. 
3. Curado MP, Edwards B, Shin HR, Storm H, Ferlay J, Heanue M, Boyle $P$, editors. Cancer incidence in five continents IX. IARC Scientific Publications No 160. Lyon: IARC;2007.

4. Aucamp PJ, Björn LO. Questions and Answers about the Environmental Effects of the Ozone Layer Depletion and Climate Change: 2010 Update. Environmental Effects Assessment Panel: 2010, United Nations Environmental Programme.

5. Tucker MA, Goldstein AM. Melanoma etiology: where are we? Oncogene 2003;22(20):3042-52.

6. de Vries E, Bray F, Coebergh JWW, Parkin DM. Changing Epidemiology of malignant cutaneous melanoma in Europe 1969-1997: rising trends in incidence and mortality, but recent stabilisations in Western Europe and decreases in Scandinavia. Int J Cancer 2003;107(1):119-26.

7. Levi F, Erler G, Te VC, Randimbison L, La Vecchia C. Trends in skin cancer incidence in Neuchatel 1976-98. Tumori 2001;87(5):288-9.

8. Levi F, Te VC, Randimbison L, Erler G, La Vecchia C. Trends in skin cancer incidence in Vaud: an update, 1976-1998. Eur J Cancer Prev 2001;10(4):371-3.

9. European Cancer Observatory. Melanoma of skin. 2008 [cited 2011 Dec 5]. Available from http://eu-cancer.iarc.fr/EUCAN/Cancer. aspx? Cancer $=20$.

10. Cancer Incidence 2008 in the Czech Republic. IHIS of The Czech Republic [cited 2011 Dec 5]. Available from http://www.uzis.cz/ publikace/novotvary-2008.

11. Epidemiology of malignant tumors in the Czech Republic [cited 2011 Dec 5]. Available from http://www.svod.cz/?sec=aktuality\&lang=en.

12. Surveillance Research Program - Cancer Control and Population Sciences [cited 2011 Dec 5]. Available from http://surveillence.cancer.gov/joinpoint/aapc.html.

13. Richardson B, Price A, Wagner M, Williams V, Lorigan $P$, Browne $S$, Miller JG, Mac Neil S. Investigation of female survival of metastatic melanoma. Br J Cancer 1999;80:2025-33.

14. Arora RS, Alston RD, Eden TO, Moran A, Geraci M, O'Hara C, Birch JM. Cancer at ages 15-29 years: The contrasting incidence in India and England. Pediatric Blood and Cancer 2012;58(1):55-60.

15. Illig L. Epidemiologic aspects of malignant melanoma. (Review) Anticancer Research 1987;7(6):1309-14.

16. Franco-Lie I, Iversen T, Robsahm TE, Abdelnoor M. Incidence trends of melanoma of the skin compared with other localisations, in the Norwegian population, 1956-2005. Annals of Oncology 2011;22(6):1443-50.

17. Van Der Aa MA, De Vries E, Hoekstra HJ, Coebergh JWW, Siesling S. Sociodemographic factors and incidence of melanoma in the Netherlands, 1994-2005. European Journal of Cancer 2011;47(7):1056-60.

18. Grant WB. Solar ultraviolet irradiance and cancer incidence and mortality. Advances in Experimental Medicine and Biology 2008;624:16 30.
19. Buettner PG, MacLennan R. Geographical variation of incidence of cutaneous melanoma in Queensland. Australian Journal of Rural Health 2005,16(5):269-77.

20. Townsend JS, Pinkerton B, McKenna SA, Higgins SM, Tai E, Steele CB, Derrick SR, Brown C. Targeting children through school-based education and policy strategies: Comprehensive cancer control activities in melanoma prevention. Journal of the American Academy of Dermatology 2011;65(5 Suppl 1):S104-13.

21. Nikolau V, del Marmol V, Stratigos AJ. The role of public education in the early detection of melanoma. Expert Review of Dermatology 2009;4(2):119-30.

22. Fisher DE, James WD: Indoor tanning: Science, behavior, and policy. N Engl J Med 2010;363:901-3.

23. International Agency for Research on Cancer Working Group on artificial ultraviolet (UV) light and skin cancer: The association of use of sunbeds with cutaneous malignant melanoma and other skin cancers: A systematic review. Int J Cancer 2007;120:1116-22.

24. El Ghissassi F, Baan R, Straif K, Grosse Y, Secretan B, Bouvard V, Benbrahim-Tallaa L, Guha N, Freeman C, Galichet L, Cogliano V, on behalf of the WHO International Agency for Research on Cancer Monograph Working Group. A review of human carcinogens - Part D: radiation. Lancet Oncol. 2009;10:751-2.

25. Robinson JK, Rademaker AW. Sun protection by families at the beach. Journal of American Academy of Dermatology 1998;152:46670.

26. Lupton D, Gaffney D. Discourses and practices related to sun tanning and solar protection among young Australians. Health Education Research 1996;11:147-59.

27. Wilchstrom L. Predictors of Norwegian adolescents' sunbathing and use of sunscreen. Health Psychology 1994;13:412-20.

28. Tucker MA. Melanoma Epidemiology. Hematology/Oncology Clinics of North America 2009;23(3):383-95.

29. Garbe C, Leiter U. Epidemiology of melanoma and nonmelanoma skin cancer-the role of sunlight. Advances in Experimental Medicine and Biology 2008;624:89-103.

30. Van Der Leest RJT, De Vries E, Bulliard JL, Paoli J, Peris K, Stratigos AJ, Trakatelli M, Maselis TJ, Situm M, Pallouras AC, Hercogova J, Zafirovik Z, Reusch M,Olah J, Bylaite M, Dittmar HC, Scerri L, Correia O, Medenica L, Bartenjev I, Guillen C, Cozzio A, Bogomolets OV, del Marmol V. The Euromelanoma skin cancer prevention campaign in Europe: Characteristics and results of 2009 and 2010. Jurnal of the European Academy of Dermatology and Venereology 2011;25(12):1455-65.

31. Malina L, Polášková S, Pokorný A. The use of photoprotection in children of Prague agglomeration, Casopis Lekaru Ceskych 2006;145(8):662-4.

32. Greinert R, Boniol, M. Skin cancer - Primary and secondary prevention (information campaigns and screening) - With a focus on children \& sunbeds, Prog Biophys Mol Biol 2011;107(3):473-6.

33. Bauer J. Prevention of malignant melanoma. Onkologe, 2012;18(3),224-9. doi:10.1007/s00761-011-2096-7 